\title{
Modeling of Gearless Wind Power Transfer
}

\author{
Ayana Pusha, Afshin Izadian, Senior Member, IEEE, Sina Hamzehlouia, Nathaniel Girrens, and Sohel Anwar, Member, ASME \\ Purdue School of Engineering and Technology, IUPUI \\ Indianapolis, IN, 46202, USA \\ aizadian@iupui.edu
}

\begin{abstract}
In this paper, a gearless hydraulic wind energy harvesting and transfer system is mathematically modeled and verified by experimental results. The energy is harvested by a low speed-high torque wind turbine connected to a high displacement hydraulic pump, which is connected to hydraulic motors. The quality of transferred power from the wind turbine to the generator is important to maintaining the systems power balance, and frequency droop control in gridconnected applications, and to ensure that the maximum output power is obtained. The gearless wind power transfer technology may replace the current energy harvesting system to reduce the cost of operation and increase the reliability of wind pow er generation.
\end{abstract}

\section{INTRODUCTION}

Wind is the fastest growing and most widely used form of the emerging renewable energy technologies in the generation of electricity. Due to the many advances in wind generation technology, the potential for wind as a power source is immense [1]. For a traditional wind power generation system to harvest wind energy and produce electric power, the required components include a wind turbine, gearbox, and a generator. These components, the gearbox specifically, are expensive, bulky, and require regular maintenance, which makes the wind energy production expensive. By eliminating the gearbox and coupling the wind turbine to a hydraulic transmission system, the capital and the operation cost of the wind power plant could be reduced considerably. The hydraulic transmission system also allows for the integration of multiple wind turbines to one central generation unit, unlike the traditional wind power generation.

A Hydraulic Transmission System (HTS) can be defined as a 'pump-controlled motor'. In general, it consists of a displacement pump driven by the prime-mover and one or more either fixed or variable-displacement motors. The hydraulic transmission uses the pump to convert the input mechanical energy into pressurized fluid, hydraulic hoses to deliver and distribute the potential energy to the energy consumers, and the motor(s) to convert the potential energy back to mechanical energy [2]. A HTS is identified as an exceptional means of power transmission when variable output velocity is required in engineering applications in the fields of manufacturing, automation, and heavy duty vehicles[3]. They offer fast response times, maintain precise velocity under varying loads[4], including high durability and the ability to produce large forces at high speeds[5]. It also offers a more decoupled dynamic allowing for multiple input/multiple output configurations not permitted by its electrical counterpart but has had a slow transition into the powering of wind turbines due to lower energy efficiency, leakage, and noise[6].

To examine power transfer efficiency in a hydraulic transmission system, the gearbox has been eliminated and replaced with a fixed displacement hydraulic pump coupled to two fixed displacement hydraulic motors and generators by way of high pressure hydraulic piping. The wind turbine is of variable speed which offers increased efficiency in capturing the energy from the wind over a wider range of wind speeds along with better power quality and the ability to regulate the power factor, by either consuming or producing reactive power [1]. The power transferred from the wind turbine to the generator is important to maintaining the systems active, power balance, or droop frequency control, when connected to a network and to ensure that the maximum $[7,8]$ output power is obtained for a certain wind speed.

When there is a change present in the real power demand at a point in the network, it is reflected throughout the system by a fluctuation in frequency. If a drop in frequency occurs the generator will decelerate at a rate determined by the moment of inertia plus all the masses connected to its shaft. This results in the conversion of kinetic energy of the generator to electrical energy thus giving a power surge. If there is an increase in the system frequency, the inverse is true [9]. System inertia plays an extremely important role as it determines the sensitivity of system frequency to supply demand imbalances. The lower the system inertia, the faster the frequency will change if a variation in load or generation occurs [1].

A mathematical model of the system is therefore required to consider the system dynamics and be used in control system development. With the mathematical model of this system, an enhanced understanding of the HTS through analysis can be gained. It can be determined which factors are of greater importance in the system and how different parts of the system are related. The quantitative results obtained from the mathematical model can then be compared to experimental data to identify the strengths and weaknesses of the model.

This paper investigates a gearless hydraulic wind energy harvesting system that is mathematically modeled and compared to a model designed using the SimHydraulics toolbox available by Matlab/Simulink. The results produced by both simulations are then verified by experimental data to demonstrate the quality of power transfer from a high torque/low speed wind turbine to a main and auxiliary highspeed generator. The efficiency of the system is derived from experimental data. In Section II, the mathematical model of the hydraulic transmission system is designed. The 
mathematical model is compared to the model built with the SimHydraulics toolbox in Section III. Section IV verifies the both simulations with experimental data. Conclusions are presented in Section V.

\section{MATHEMATICAL MODEL OF POWER TRANSFER}

To mathematically model the gearless energy transfer system we will create a hydraulic circuit and obtain the expression of individual components. The model and simulation results obtained from this energy transfer system will be verified through experimental data.

A schematic diagram of the hydraulic transmission system considered for this work is given in Figure 1. The fixed displacement pump, driven by a wind turbine, is coupled to two fixed displacement hydraulic motors to which it supplies hydraulic power. A pressure relief valve is used to protect the system from excessive pressure. The components of the hydraulic power transfer circuit and their governing equations are illustrated below.

\section{a) Fixed Displacement Pump}

In the hydraulic transmission, shown in Figure 1, the output shaft velocity of the hydraulic motors is controlled by the flow rate of the hydraulic fluid, which is supplied from the hydraulic pump [2]. As mentioned earlier, the pump is driven by a wind turbine. In this model, the flow rate is being controlled by varying the shaft velocity of the fixed displacement pump.

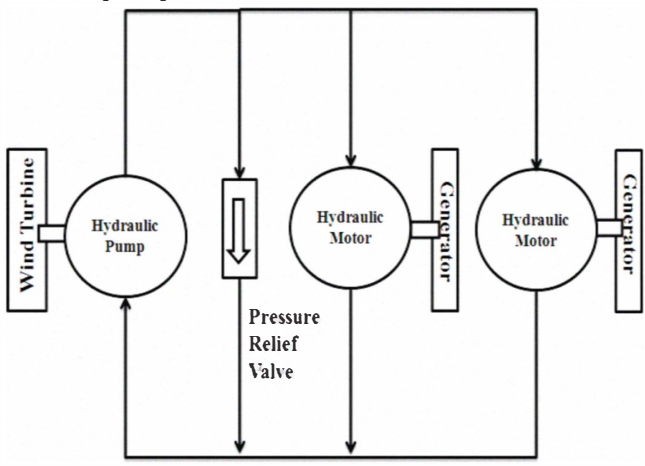

Fig. 1. Hydraulic Transmission System Block Diagram

The flow that a fixed displacement pump generates is modeled as a function of pump displacement, shaft velocity, and the leakage coefficient [10] as

$$
\begin{aligned}
Q_{p} & =D_{p} \omega_{p}-k_{\text {leak }} P \\
k_{\text {leak }} & =\frac{k_{H P}}{v \rho}, \\
k_{H P} & =\frac{D \omega_{\text {nom }}\left(1-\eta_{v}\right) v_{\text {nom }} \rho}{p_{\text {nom }}},
\end{aligned}
$$

where $Q_{p}$ is the pump flow rate, $D_{p}$ is the pump displacement, $\omega_{p}$ is the angular velocity of the pump, $k_{\text {leak }}$ is the leakage coefficient, $P$ is the system pressure, and $k_{H P}$ is the HagenPoiseuille coefficient which is calculated using the following parameters: nominal angular velocity $\left(\omega_{\text {nom }}\right)$, nominal fluid kinematic viscosity $\left(v_{\text {nom }}\right)$, nominal pressure $\left(p_{\text {nom }}\right)$, fluid density $(\rho)$, and as volumetric efficiency $\left(\eta_{v}\right)$.

\section{b) Pressure Relieve Valve}

The pressure relieve valve is modeled as a close/open valve energized at a preset pressure value. The valve is open if the pressure exceeds the preset value, and for pressures below this value, the valve is closed. The following two equations are given for passing flow rate through the pressure relieve valve:

$$
\begin{array}{ll}
Q_{v}=k_{z b}\left(P-P_{b}\right) & \text { if } P>P_{b}, \\
Q_{v}=0 & \text { if } P \leq P_{b},
\end{array}
$$

where $Q_{v}$ is the flow rate through the valve, $k_{z b}$ is the flow discharge coefficient, and $P_{b}$ is the valve preset pressure setting.

\section{c) Fluid Compressibility}

In connecting the wind turbine to the motors in our prototype, we have used flexible hoses. The dynamics of these pressurized hoses are modeled as volume with a fixed bulk modulus. The fluid compressibility $[4,11]$ relation can be illustrated as

$$
\frac{d P}{d t}=\frac{\beta}{V}\left(Q_{p}-Q_{m}-Q_{v}\right),
$$

where $\beta$ is the fluid bulk modulus and $V$ is the fluid volume subjected to pressure effect.

This equation also provides the resultant pressure at a given flow rate. It is assumed that pressure drop in the hydraulic hose is negligible.

\section{d) Hydraulic Motor and Load}

Like hydraulic pumps, the governing equation of motors is a function of displacement factor, leakage coefficient, and flow rate and is expressed as [12]

$$
Q_{m}=D_{m} \omega_{m}+k_{\text {leak }} P \text {, }
$$

where $Q_{m}$ is the pump flow rate, $D_{m}$ is the pump displacement, and $\omega_{m}$ is the angular velocity of the motor.

The motor's moment of inertia, damping coefficient, and the load connected to the motor's shaft determine the torque dynamics, and can be expressed as

$$
\begin{gathered}
T_{m}=I_{m} \dot{\omega}_{m}+B_{m} \omega_{m}+T_{l}, \\
T_{m}=\frac{D_{m} P}{2 \pi},
\end{gathered}
$$

where $T_{m}$ is the torque produced by the motor, $I_{m}$ is the inertia moment of motor, $B_{m}$ is the damping coefficient of motor, and $T_{l}$ is the load torque.

The output shaft velocity of the motor under loading condition (speed drop due to loading) in the mathematical modeling of the system can be determined using equation (8) as

$$
\begin{gathered}
I_{m} \dot{\omega}_{m}=T_{m}-B_{m} \omega_{m}-T_{l}, \\
\dot{\omega}_{m}=\frac{T_{m}-B_{m} \omega_{m}-T_{l}}{I_{m}},
\end{gathered}
$$




\section{e) Hydraulic Transmission System}

The overall hydraulic transmission system (HTS) comprises of a combination of the mathematical model of the system components mentioned above. Mathematical expression of the overall system can be obtained from the block diagram shown in Figure 2. Equations (6) and (11) are the structure for which the mathematical model of the HTS system is built. We have used Matlab/Simulink to carry out the simulation results and to solve these nonlinear equations.

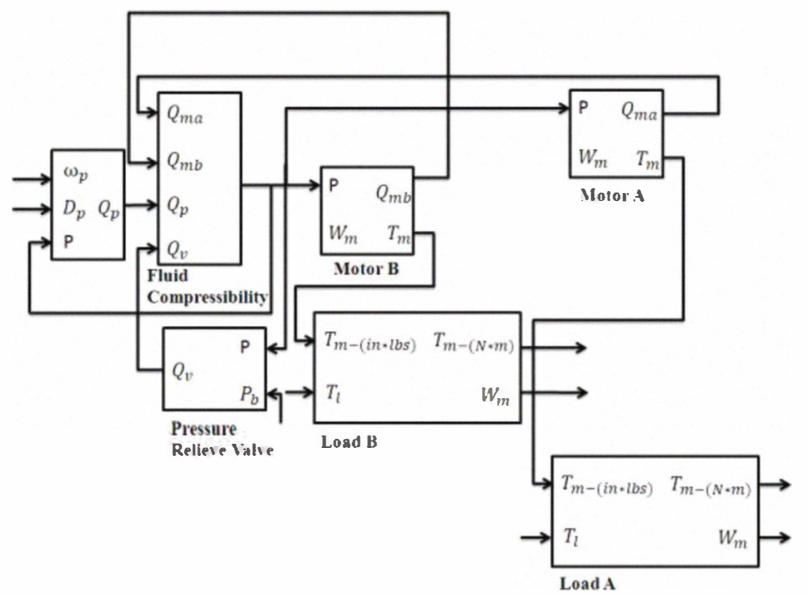

Fig. 2. Mathematical Model and Block Diagram of Hydraulic Power Transfer System.

\section{SimUlation RESUlts}

As verification to our mathematical modeling, the HTS was also simulated using SimHydraulics, a hydraulics toolbox provided by Matlab and Simulink $\AA$, and compared to the mathematical model obtained in Figure 2. The following assumptions were considered to develop the model [12]:

1. The hydraulic fluid is assumed incompressible.

2. No loading is considered on pump and motor shafts (i.e. inertia, friction, spring and etc.).

3. Leakage inside the pump and motor are assumed to be linearly proportional to their respective pressure differential[13].

In simulations, a fixed displacement pump with a displacement of $0.517 \mathrm{in}^{3} / \mathrm{rev}$ provides hydraulic fluid to a main motor (Motor A) and auxiliary motor (Motor B) with displacements of $0.097 \mathrm{in}^{3} / \mathrm{rev}$ and $0.065 \mathrm{in}^{3} / \mathrm{rev}$. Input signals, with varying velocities ranging from 283 RPM to 580 RPM, are applied to the shaft of the pump.

The torque and velocity of Motor A and Motor B were measured and compared to the torque and velocity output of the mathematical model obtained in this paper. The accuracy of the mathematical model is confirmed by comparing the mathematical model to the SimHydraulic model and later on with experimental data.

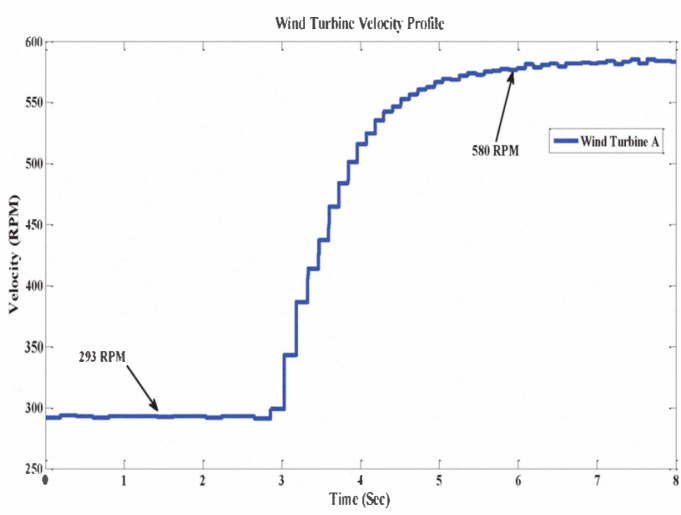

Fig. 3. Wind Turbine Input Velocity (Experimental Data)

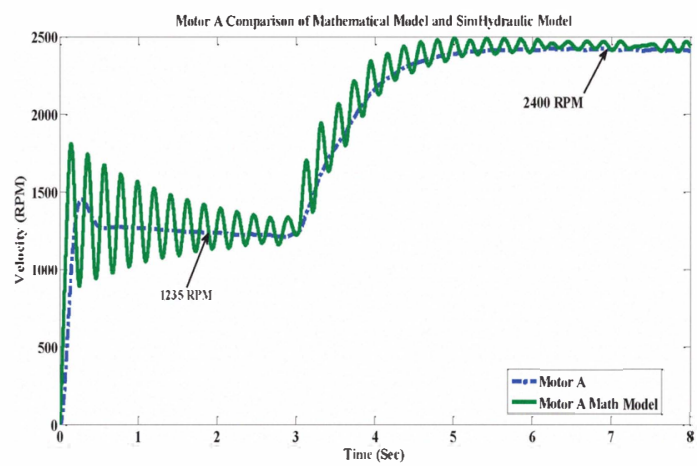

Fig. 4. Motor A Velocity Comparison of Mathematical Model and SimHydraulic Model

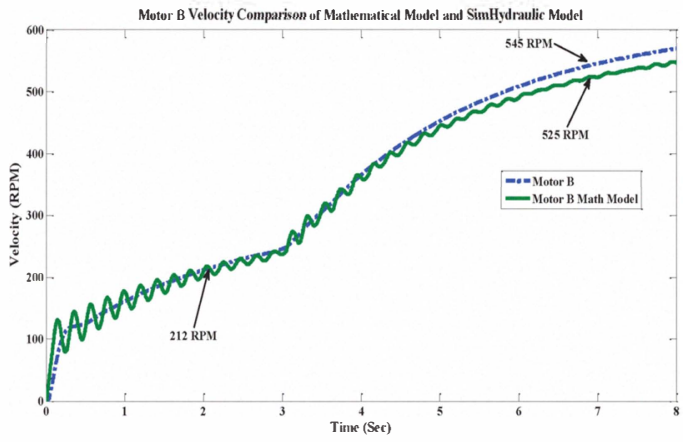

Fig. 5. Motor B Velocity Comparison of Mathematical Model and SimHydraulic Model

The output velocity for Motor A and Motor B for both the mathematical model and the simulated HTS illustrate that there is minimal variation in the final value; however, the dynamics of the speed variation and specifically the overshoot is not shown in the mathematical model.

\section{EXPERIMENTAL DATA}

After completing simulations on the mathematical model and SimHydraulics Matlab model, experimental testing was performed on the gearless hydraulic power transfer system shown in Figure 6. Velocities of 293 to 580 RPM were applied to the pump shaft over period of 8 seconds to supply hydraulic fluid to Motor A and Motor B. The output velocity of Motor A and Motor B was then recorded and compared to 
the output velocities of Motor A and Motor B produced during simulations.

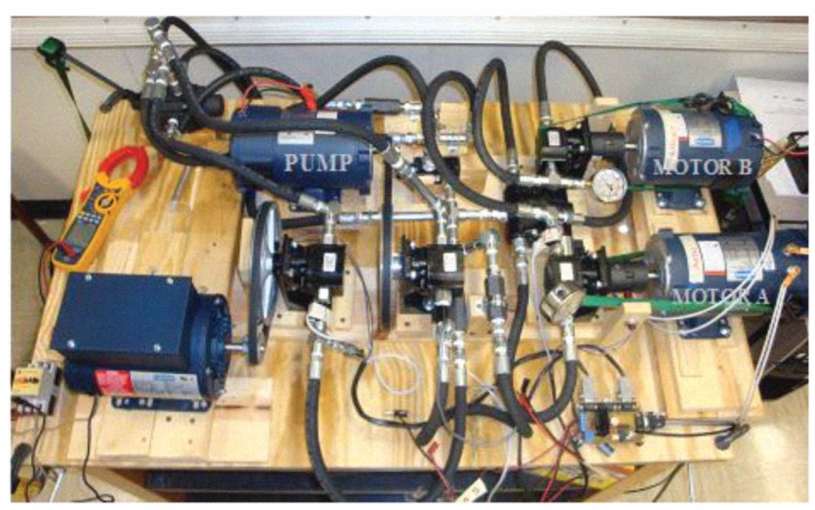

Fig. 6. Experimental Setup of Gearless Power Transfer System

The experiment performed applied a step velocity change at the input shaft of the hydraulic pump so that the system response in the velocities of motors $\mathrm{A}$ and $\mathrm{B}$ could be observed. The velocity measured at Motor A during testing yielded results of a final output of 2222 RPM, while Motor B yielded results of a final output of 680 RPM.

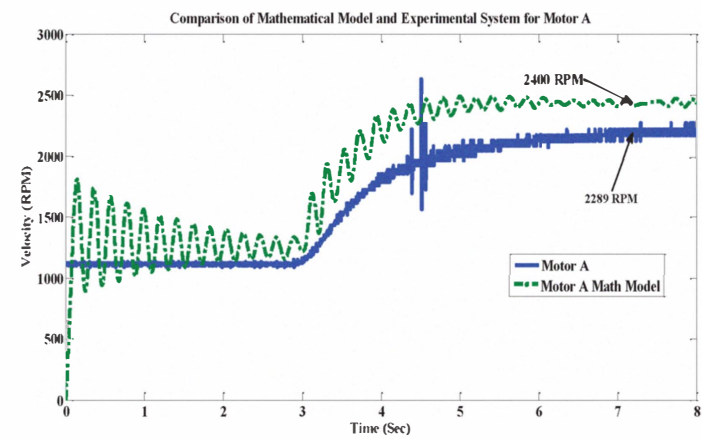

Fig. 7. Velocity Comparison of Mathematical Model and Experimental System for Motor A

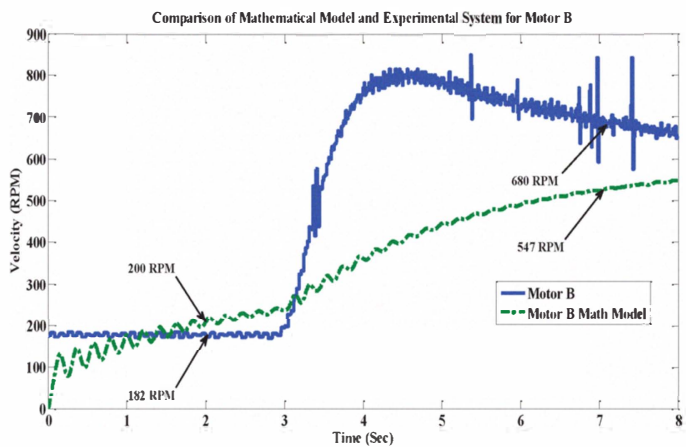

Fig. 8. Velocity Comparison of Mathematical Model and Experimental System for Motor B

\section{CONCLUSION}

In this paper an energy transmission system being operated by a wind turbine was mathematically modeled with one fixed displacement pump and two hydraulic motors. The obtained mathematical model was compared to a model designed using the SimHydraulic toolbox in
Matlab/Simulink and with the experimental results obtained from a prototype of the hydraulic system. The simulation and experimental results show that the mathematical model is equivalent to the model built using the SimHydraulics toolbox in Matlab. The experimental data illustrated that the gearless hydraulic power transfer system built behaves as the simulated models.

\section{ACKNOWLEDGEMENT}

This work was supported by a grant from IUPUI Solution Center.

\section{REFERENCES}

[1] G. Lalor, et al., "Frequency control and wind turbine technologies," Ieee Transactions on Power Systems, vol. 20, pp. 1905-1913, 2005.

[2] K. Wu, et al., "Modelling and identification of a hydrostatic transmission hardware-in-the-loop simulator," International Journal of Vehicle Design, vol. 34, pp. 52-64, 2004.

[3] K. Dasgupta, "Analysis of a hydrostatic transmission system using low speed high torque motor," Mechanism and Machine Theory, vol. 35, pp. 1481-1499, Oct 2000

[4] A. V. Akkaya, "Effect of bulk modulus on performance of a hydrostatic transmission control system," Sadhana-Academy Proceedings in Engineering Sciences, vol. 31, pp. 543-556, Oct 2006.

[5] G. A. Sohl and J. E. Bobrow, "Experiments and simulations on the nonlinear control of a hydraulic servosystem," Ieee Transactions on Control Systems Technology, vol. 7, pp. 238-247, Mar 1999.

[6] S. Habibi and A. Goldenberg, "Design of a new high-performance electrohydraulic actuator," IEEE-Asme Transactions on Mechatronics, vol. 5, pp. 158-164, Jun 2000.

[7] K. Pandiaraj, et al., "Distributed load control of autonomous renewable energy systems," Ieee Transactions on Energy Conversion, vol. 16, pp. 14-19, 2001

[8] Z. X. Miao, et al., "Wind Farms With HVdc Delivery in Inertial Response and Primary Frequency Control," Ieee Transactions on Energy Conversion, vol. 25, pp. 1171-1178, 2010.

[9] L. Holdsworth, et al., "Power system frequency response from fixed speed and doubly fed induction generator based wind turbines," Wind Energy, vol. 7, pp. 21-35, 2004

[10]http://www.mathworks.com/help/toolbox/physmod/hydro/ref/fixeddispl acementpump.html Fixed Displacement Pump.

[11] R. Z. a. A. Alleyne, "A Model Reference Load Controller with Adaptation Using a two Stage Pressure Relief Valve," Proceedings of the American Control Conference, pp. 3949-3954, 2001.

[12] http://www.mathworks.com/help/toolbox/physmod/hydro/ref/hydraulic motor html,"Hydraulic Motor."

[13] a. G. R. T. G.C. van Kooten, "Wind Power Development: Economics and Policies," in Policy Working Paper 4868, T. W. B. D. R. G. E. a. E. Team, Ed., ed, March 2009. 